\title{
Subacute Toxicity Assessment of Acephate and it's Amelioration by Picrorhiza kurroa in Female Wistar Rats
}

\author{
S. A. Londhe*, G. R. Gangane and S. D. Moregaonkar \\ Department of Veterinary Pathology, College of Veterinary and Animal Sciences, \\ MAFSU, Parbhani, (MS), India \\ *Corresponding author
}

\begin{abstract}
A B S T R A C T
Keywords

Acephate, Wistar rats, Picrorhiza

kurroa, and

Histophological studies

Article Info

Accepted:

28 November 2020

Available Online:

10 December 2020

The experimental study was conducted on 30 female wistar rats through five groups for 28 days. The group I and III served as control groups. The rats of group IV and V were treated with Acephate and Picrorhiza kurroa and group II was treated with only Acephate. Amongst those, group II and IV showed non-significant reduction in mean body weight and group II, IV and V did not showed any behavioural changes, except, dullness and lethargy. Group II and IV Non-significant variation in mean relative organ weights of liver, kidneys, spleen and Adrenal gland were observed. Grossly, liver and brain showed mild congestion with minimal and focal haemorrhages on kidneys. On histopathology, liver showed focal to multifocal congestion, dilatation of sinusoidal spaces, dilatation of central vein, fatty changes, cytoplasmic rarefication and MNC infiltration. Kidneys revealed mild to moderate congestion, vacuolar, hydropic, cystic degeneration, haemorrhagic cystic degeneration, coagulative necrotic changes, hyaline cast in lumen of exposed tubules and MNC infiltration. There was lymphocyte depletion, minimal to mild congestion in spleen. Neurotoxicity was characterized by vacuolar degeneration and congestion in brain. Intestines revealed acute catarrhal inflammatory changes. Heart showed congestion, minimal to mild haemorrhages and fragmentation. Adrenal glands showed congestion.
\end{abstract}

\section{Introduction}

At present, India is the largest producer of pesticides in Asia, and ranks $12^{\text {th }}$ in the world for the use of pesticides, with an annual production of 90,000 tons 5 . A vast majority of the population in India (56.7\%) is engaged in agriculture and is therefore exposed to the pesticides used in agriculture ${ }^{7,8}$. Pesticides being used in agricultural tracts are released into the environment and come into human contact directly or indirectly. Organophosphorus (OP) insecticide selfpoisoning is a major health problem, with approximately 200,000 deaths each year ${ }^{1}$.

Acephate is an organophosphate foliar spray insecticide of moderate persistence with residual systemic activity of about 10-15 days. Acephate and its primary metabolite, methamidophos, are toxic to Heliothis spp. that are considered resistant to other 
organophosphate insecticides ${ }^{6}$. National Pesticide Information Centre described that people exposed to acephate had nausea, diarrhoea, abdominal cramps, shaking, sweating, rapid heart rate, dizziness and confusion. Symptoms usually begin within minutes or hours after exposure.

Picrorhiza kurroa is an important medicinal plant used in traditional as well as modern medicines. It is used in treatment of liver disorder, fever, asthma, jaundice caused by environmental pollution, industrial toxicants, food adulteration, malnutrition, excessive consumption of alcohol and certain infections $^{2}$. Considering the present status of use of Acephate by the agrerians and the trend of herbal medication in treating many disorders, the present trial was conducted with following objective.

\section{Objective}

To assess toxicopathological effect of Acephate in female wistar rats and it's amelioration by Picrorhiza kurroa through body weight, symptomatology, relative organ weights and pathomorphological studies.

\section{Materials and Methods}

\section{Female Wistar Rats}

Thirty female Wistar rats of 6-8 weeks age having 140-160 gm body weight. The female Wistar rats were procured from M/S Worckdht Research center, MIDC Aurangabad, (MS) 431006.

\section{Collection of Acephate Pesticide}

Acephate (O,S dimethyl acetyl phosphoramidothioate) was procured from Department of Pesticide, College of Agriculture, Vasantrao Naik Marathwada Krishi Vidyapeeth, Parbhani (MS).

\section{Feeding}

Rats were provided with standard pellet feed (M/S L.R. Pharmaceutical Company, Parbhani, Maharashtra, India).

\section{Preparation of Acephate doses}

Acephate pesticide dose was calculated as $1 / 20^{\text {th }}$ of $\mathrm{LD}_{\mathbf{5 0}}\left(1127 \mathrm{mg} / \mathrm{kg}^{22)}\right.$ of female wistar rats. Acephate is a powder form pesticide which was mixed with vehicle propylene glycol and fed daily through oral gavage to the experimental rats.

\section{Picrorhiza kurroa Powder}

Dried powder of a plant of Picrorhiza kurroa (kutki) was procured from the local market of Parbhani.

\section{Preparation of plant aqueous extract}

\section{Extraction of Plant with Hot water ${ }^{11}$}

$250 \mathrm{gm}$ dried plant powder of Picrorhiza kurroa mixed with $500 \mathrm{ml}$ distilled water.

Prepared mixture was boiled for $30 \mathrm{~min}$. cool it and filtered with whatman filter paper no. 42.

Extract was kept into conical flask and pluged with cotton swab and then liquid extract was kept at $2-4^{\circ} \mathrm{C}$ till its use

\section{Experimental design}

\section{Body weights}

Weekly body weights of experimental rats were taken and computed.

\section{Symptomatology}

All the experimental rats were observed twice daily throughout experimental period. 


\section{Relative organ weights}

At $28^{\text {th }}$ day of study period, Liver, kidney, spleen and Adrenal gland were excised, weighed and expressed.

\section{Gross and Histopathological study}

At the time of organ weighing, gross changes, if any, were recorded. Representative tissues were collected in $10 \%$ formal saline from organs and processed for histopathological studies.

\section{Statistical analysis}

The data generated in respect of body weight and relative organ weights were statistically analysed by Completely Randomized Design $(\mathrm{CRD})^{19}$ to know the statistical differences between means at different intervals in each group.

\section{Results and Discussion}

\section{Average body weight}

Table 2 depicts mean body weights of experimental rats at weekly intervals. In female rats of Acephate toxicated groups (II and IV), the average body weight were reduced non-significantly than the control group rats. However, female rats of group V showed slight improvement in mean body weights as compared to Acephate toxicated rats, whereas, the female rats of group III did not show any significant variation at studied intervals. At $28^{\text {th }}$ day of trial, the percent body weight gain in female rats of group I, II, III, IV and V when assessed, found to be $7.53 \%$, $2.97 \%, \quad 7.27 \%, \quad 4.21 \%$ and $5.37 \%$ respectively. The percent body weight gain in female rats of group II and IV indicated reduction than the respective control group female rats body weight gain. However, the percent body weight gain in female rats of group V showed improvement. The body weight gain in female rats of plant control group remained comparable with that of respective control group.

The decrease in body weight gain in Acephate toxicities could be preliminary attributed to the effect of insecticide on gastrointestinal tract resulting in decreased appetite and absorption of nutrients from gut or might be an indication of direct toxicity or stressogenic activity of insecticide compound ${ }^{3,9,10}$. The reduction in body weight gain also could be attributed to anorectic properties of insecticides $^{14}$.

Increase in body weight gain in Picrorhiza kurroa treated groups could be due to its beneficial properties like appetizer and immunomodulent ${ }^{15}$.

\section{Symptomatology}

The experimental rats of all groups did not reveal any apparent behavioural changes, except, hypersensitivity just after Acephate administration, dullness and lethargy in female rats of group II and IV. The signs observed in present study are in close approximation with earlier reports ${ }^{3,13}$.

\section{Relative organ weight}

At $28^{\text {th }}$ day of trial, the mean relative weights of liver, kidneys, spleen and adrenal gland of group I, II, III, IV and V remained comparable amongst themselves and their mean values obtained are shown in Table 3 . The use of Acephate at specified dose level in present study might have not been so toxic to affect relative organ weight significantly. The observations in present study are in at par with the reports of earlier authors ${ }^{17}$. Increase in mean liver weights of experimental rats in toxicity studies have been reported by earlier researchers $^{21,24}$. 
Table.1 Details of Experimental groups of female Wistar rat

\begin{tabular}{|c|l|c|c|}
\hline Groups & \multicolumn{1}{|c|}{ Treatment } & $\begin{array}{c}\text { No. of } \\
\text { Animals }\end{array}$ & Route \\
\hline I & $\begin{array}{l}\text { Control group with vehicle- ad } \\
\text { libitum feed and water daily for } 28 \\
\text { days }\end{array}$ & 06 & $\begin{array}{c}\text { Normal feeding } \\
\text { and watering }\end{array}$ \\
\hline II & $\begin{array}{l}\text { Acephate @ 56.35 mg/kg with } \\
\text { vehicle }\end{array}$ & 06 & By oral gavage \\
\hline III & $\begin{array}{l}\text { Picrorhiza kurroa aqueous extract @ } \\
\text { 50 mg/kg body weight }\end{array}$ & 06 & By oral gavage \\
\hline IV & $\begin{array}{l}\text { Acephate @ 56.35 mg/kg } \\
+ \text { Picrorhiza kurroa aqueous } \\
\text { extract@ 25 mg/kg body weight }\end{array}$ & 06 & By oral gavage \\
\hline V & $\begin{array}{l}\text { Acephate @ 56.35 mg/kg } \\
+ \text { Picrorhiza kurroa aqueous } \\
\text { extract@ 50 mg/kgbody weight } \\
\text { Total }\end{array}$ & 06 & By oral gavage \\
\hline
\end{tabular}

Table.2 (Mean \pm S.E.) Average weekly body weight (gm/week) in experimental rats at different intervals of study

\begin{tabular}{|c|c|c|c|c|c|}
\hline \multirow{2}{*}{ Groups } & \multicolumn{5}{|c|}{ Weekly Body weight of rats (gm/week) } \\
Intervals of study \\
\cline { 2 - 7 } & $\mathbf{0}$ Day & $\mathbf{7}^{\text {th }}$ Day & $\mathbf{1 4}^{\text {th }}$ Day & $\mathbf{2 1}^{\text {st }}$ Day & $\mathbf{2 8}^{\text {th }}$ Day \\
\hline I & $201.33 \pm 09.07$ & $203.66 \pm 08.13$ & $208.00 \pm 10.38$ & $215.50 \pm 06.46$ & $216.50 \pm 07.54$ \\
\hline II & $201.66 \pm 04.50$ & $201.83 \pm 02.92$ & $199.66 \pm 05.44$ & $205.66 \pm 07.15$ & $207.66 \pm 05.81$ \\
\hline III & $197.00 \pm 09.05$ & $199.16 \pm 08.23$ & $208.83 \pm 08.40$ & $209.83 \pm 08.53$ & $211.33 \pm 08.20$ \\
\hline IV & $205.50 \pm 07.88$ & $203.83 \pm 08.50$ & $201.33 \pm 08.39$ & $211.16 \pm 07.84$ & $214.16 \pm 07.87$ \\
\hline V & $204.50 \pm 09.35$ & $204.00 \pm 9.36$ & $208.00 \pm 10.47$ & $215.16 \pm 09.51$ & $215.50 \pm 10.17$ \\
\hline Statistics & NS & NS & NS & $\mathbf{N S}$ & $\mathbf{N S}$ \\
\hline
\end{tabular}

Table.3 (Mean \pm S.E) values of Relative organ weights of Liver, kidneys, Spleen and Adrenals in experimental rats

\begin{tabular}{|c|c|c|c|c|}
\hline \multirow{2}{*}{ Groups } & \multicolumn{4}{|c|}{ Relative organ weights of female experimental rats } \\
\cline { 2 - 5 } & Liver & Kidney & Spleen & Adrenals \\
\hline I & $3.17 \pm 0.21$ & $0.65 \pm 0.06$ & $0.24 \pm 0.02$ & $0.05 \pm 0.00$ \\
\hline II & $3.16 \pm 0.21$ & $0.68 \pm 0.06$ & $0.25 \pm 0.03$ & $0.05 \pm 0.00$ \\
\hline III & $3.28 \pm 0.08$ & $0.74 \pm 0.07$ & $0.30 \pm 0.03$ & $0.04 \pm 0.00$ \\
\hline IV & $3.22 \pm 0.16$ & $0.61 \pm 0.02$ & $0.18 \pm 0.01$ & $0.03 \pm 0.00$ \\
\hline V & $3.48 \pm 0.07$ & $0.64 \pm 0.02$ & $0.23 \pm 0.02$ & $0.05 \pm 0.00$ \\
\hline Statistics & NS & NS & NS & NS \\
\hline
\end{tabular}


Fig.1 Section of liver with dilatation of central vein, sinusoidal spaces, focal fatty changes and degenerative changes in hepatic parenchyma (H\&E 400X) Fig. 2 Note multifocal fatty changes, cytoplasmic rarefication of hepatocytes with focal congetion and MNC infiltration in liver (H\&E 400X) Fig. 3 Section of a kidney with multifocal haemorrhagic cystic degeneration and MNC infiltration (H\&E 400X) Fig. 4 Note hyaline casts in the lumen of proximal, distal convoluted tubules, multifocal degenerative changes, congsetion and $\mathrm{MNC}$ infiltration in kidney (H\&E 400X) Fig. 5 Note depletion of lymphocytes in a spleen (H\&E 400X) Fig. 6 Microphotograph of a brain with vacuolation, neuronal degeneration and minimal congestion (H\&E 400X) Fig. 7 Microphotograph of a heart with distortion of cardiac muscles and focal MNC infiltration (H\&E 400X) Fig.8 Section of a adrenal gland with congestion (H\&E 400X)
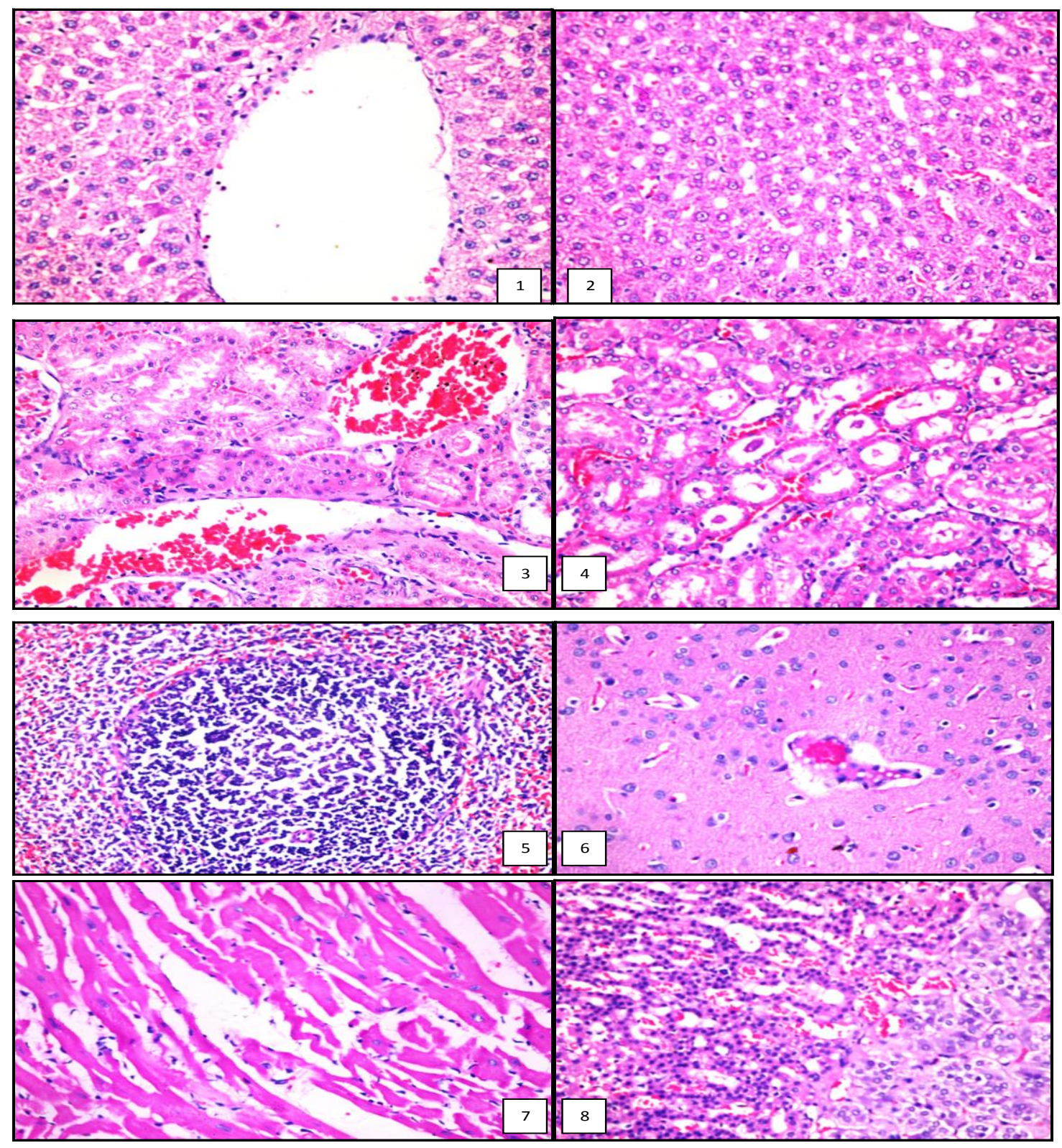


\section{Gross and Histopathological studies}

The gross pathological changes did not showed any appreciable changes in any of the organ studied except, mild congestion in liver, brain and minimal focal petechial haemorrhages in kidneys of few female rats of group II and IV.

The histoarchitectural changes noted in present trial are depicted through illustrations (Fig. 1 to 8 ).

\section{Liver}

On histopathological examination, liver of toxicated female rats of group II and IV showed minimal to moderate, focal to multifocal congestion, dilatation of sinusoidal spaces, dilatation of central vein, fatty changes mostly characterized by circumscribed vacuolation, cytoplasmic rarefication, $\mathrm{MNC}$ infiltration, degenerative changes and necrotic changes in hepatic parenchyma. Similar histopathological lesions in liver of female wistar rats of Acephate toxicated groups have been observed in earlier studies ${ }^{3,12,13}$.

Histomorphological alterations are mostly related to the metabolic capabilities of liver. As is fully established that OPs can affect the enzymatic pathways involved in the metabolism of lipids, carbohydrates and proteins. Additionally, OPs could also cause oxidative stress characterized by formation of reactive oxygen species and triggering apoptetic pathways ${ }^{20}$.

The female experimental rats of group IV and $\mathrm{V}$ were subjected to toxicities and these were also treated with Picrorhiza kurroa plant aqueous extract daily for 28 days. The plant extract used in the trial might have helped in restoration of plasma membrane permeablility including repairement of injured hepatic cells, increasing protein and nucleic acid synthesis. Also, aqueous extract of Picrorhiza kurroa might have protected the liver by its membrane stabilizing, antioxidant properties and its capabilities of counteracting free radicals ${ }^{18}$.

\section{Kidneys}

The kidney sections of female rats of group II and IV revealed mild to moderate congestion, tubular degeneration, vacuolar degeneration, hydropic degeneration, cystic degeneration, haemorrhagic cystic degeneration, coagulative necrotic changes, hyaline/proteinous casts in the lumen of proximal, distal convoluted tubules and focal to multifocal mononuclear cell infiltration. As stated by earlier researchers ${ }^{3,12,13}$ and histopathological observations in present study as observed, Acephate could lead to renal injury consequencing nephrotoxicity ${ }^{23}$.

The reduced extent and intensity of nephropathic lesions in female rats of group $\mathrm{V}$ could be probably due to multifaceted role being played by aqueous extract of Picrorhiza kurroa.

\section{Spleen}

The spleen of group II and IV on its histopathology revealed focal haemorrhages and lymphoid depletion. However, the sections of spleen of experimental rats of group I, III and $\mathrm{V}$ did not showed any appreciable changes.

\section{Intestines}

The histopathological studies of intestine of female rats of group II and IV appeared to be with mild congestion, inflammatory cell infiltration in mucosal lining, acute catarrhal inflammatory changes, minimal goblet cell hyperplasia, mild necrotic changes in the 
lymphoid areas of intestine, desquamation of epithelial linings and its exfoliation in lumen probably could be due to enteropathic effect of Acephate toxicity. However, the sections of intestines from female rats of group I, III and $\mathrm{V}$ did not showed any considerable histomorphological alterations.

\section{Heart}

The sections of heart from the rats of group I, III and V did not showed any noticeable histomorphological changes. However, the tissue sections of heart from the rats of group II and IV were with congestion, minimal to mild haemorrhages, fragmentation, distortion of myocardial fibers, focal mononuclear cell infiltration and degenerative changes in cardiac muscles.

\section{Lungs}

The lungs of female rats of almost experimental groups on its histopathological assessment revealed mild congestion and inflammatory cell infiltration indicating incidental changes, however, the sections of lungs from rats of group II and IV were with comparatively more intense histopathological changes.

\section{Ovary}

The sections of ovary did not showed any appreciable histoarchitectural change in either of the rats of almost experimental groups, except, congestion in two sections of ovaries in female rats of group II.

\section{Adrenal gland}

The histopathological examination of adrenal glands from female rats of control as well treatment groups did not revealed noticeable changes, except, minimal focal congestion in three sections of adrenal glands of female rats of group II.

\section{Skin}

The skin of female rats on its histopathology did not showed any histopathological changes. These histopathological findings observed in spleen, brain, intestines, heart, lungs, ovary and adrenal glands in present study goes well with reports of earlier researchers $^{3,13}$ who conducted studies on Acephate toxicity. The changes noted in brain and heart probably could have been resulted due to neurotoxic and cardiopathic effects of Acephate toxicity. The OP pesticides could inhibit AchE activity and elicits neurotoxicity ${ }^{23}$. The considerable recovery in histoarchitecture of studied organs in female rats of group $\mathrm{V}$ might have obtained due to multifactorial role being played by Picrorhiza kurroa aqueous extract.

In conclusion, Acephate at scheduled dose induced toxicity as supported by findings in respect to body weight, behavioural changes and pathomorphological studies. Also, the experimentally induced toxicity during the present trial has shown amelioration by aqueous extract of Picrorhiza kurroa at specified dose level as evidenced by findings recorded because of the phytochemical action of plant.

\section{Acknowledgements}

Authors are thankful to Associate Dean, College of Veterinary and Animal Sciences, Parbhani for providing facilities for conduct of research and M/s. L.R. Pharmaceutical Company, Parbhani, Maharashtra, for providing standard feed pellet for female wistar rats.

\section{References}

1. Adam Isacoff, George Bosse, Eric Fulcher and Christine Duff (2015) Atypical Presentation of an 
Organophosphorus Poisoning J. Clin. Toxicol 2015, 5: 4.

2. Bhandari P., N. Kumar, B. Singh, A. P. Gupta and P. S. Ahuja, Online HPLCDPPH method for antioxidant activity of Picrorhiza kurroa Royle ex Benth and characterization of kutyoside by ultraperformance LC electrospray ionization quadropole time of flight mass spectroscopy. Indian Journal of Experimental Biology (2009) 48: 323328.

3. Bhadaniya A.R., D.V. Joshi, B.J. Patel, V.A. Kalaria, R.J. Padodara, and H.H. Savsani, (2012) Wayamba Journal of Animal Science - ISSN: 2012-578X; 12 First Published.

4. Benbrook C.M. (1991): Sustainable Agriculture Research and Education in the field. National Academy Press. Washington, DC.

5. Chitra, G. A., V. R. Muraleedharan, T. Swaminathan and D. Veeraghavan (2006) Use of pesticides and its impact on health of farmers in South India INT. J. Occup Environ Health 12: 228-233.

6. Frank R. G.; Ritcy Braun, H. E. and McEwen, F. L. (1984). Disappearance of Acephate Residue from Beans, Carrots, Celery, Lettuce, Peppers, Potatoes, Strawberries and Tomatoes. J. Econ. Ent. 77(5): 1110- 1115.

7. Gupta P.K. Pesticide exposure-Indian sci. Toxicology (2004) 198: 83-90.

8. Goverment of India. Tenth five-year plan: 2002-2007. Planning Commission of India, New Delhi, India, (2001)513 566. <http: //planning commission. nic.in/plans/planrel/fiveyr/welcome.html $>$.

9. Gowda H., R.F. Uppal, and B.D. Garg, (1985) Effect of malathion on blood glucose, liver glycogen, plasma corticosterone and electrolytes concentrations and eosinophil count in adrenal demedullated rats. Current Sci.
54: 269-271.

10. Goyal B. S., S. K. Garg, and B. D Garg, (1986) Malathion induced hyperadrenal activity in WLH chicks. Current Science. 55: 526-528.

11. Handa Sukhdev Swami, Suman Preet Singh Khanuja, Gennaro Longo, Dev Dutt Rakesh (2008) Extraction technologies for medicinal and aromatic plants, International centre for science and high technology.

12. Manna S. and D. Bhattacharya, (2004) Repeated dose Toxicity of alfacypermethrin in rats. J. Vet. Sci. 5(3): 241-5.

13. Mishra C.S., (2014) Studies on Toxicopathology of Acephate in wistar rats \& its Amelioration with cow and goat urine distillates $\mathrm{PhD}$ thesis, submitted to the Chhattisgarh Kamdhenu Vishwavidyalaya ANJORA, DURG (C.G.)

14. Mohapatra M., and P.N. Mallick, (1998). Effect of deltamethrin on broilers. Recent Advances in Toxicology. XVII Annual Conference of Society of Toxicology, India.

15. Mohammad Ali, Shahnaz Sultana and Showkat Rasool Mir (2017) Chemical Constituents From the roots of Picrorhiza kurroa Royle Ex Benth International J. of Pharmacy and Pharmaceutical research Vol: 9 Issue: 3.

16. National Pesticide Information Center (2011) Oregon State University.

17. Preeti Sharma, Vinod Kumar, A.K. Sikka and J.S. Punia (2014) Hematological and Morphometric Studies of Imidacloprid Through Oral Administration In Swiss Albino Mice Haryana Vet. 53(2): 144-147.

18. Singh Madhulika, Vandana Tiwari, Amita Jain and Sheela Ghoshal (2005). Protective activity of picroliv on hepatic amoebiasis associated with carbon tetrachloride toxicity. Indian J. Med Res 
121, pp 676-682.

19. Snedecor G. H. and Cochran, W. G. (1994) Statistical methods. $7^{\text {th }}$ edition. Lowa State University Press, Ames, Iowa.

20. Somayyeh Karami-Mohajeri, Ahmad Ahmadipour, Hamid-Reza Rahimi and Mohammad Adollahi (2017) Adverse effects of organophosphorus pesticides on the liver: a brief summary of four decades of research Arh Hig Rada Toksikol 68: 261-275

21. Tare R.R. (2012) Toxicopathological Studies of Imidacloprid in Wistar rats M.V.Sc. thesis Submitted to MAFSU Nagpur Maharashtra.

22. United Phosphorus, Inc. (2010) Acephate
97UP Insecticide, Material data safety sheet.

23. Yurong Hou, Can Cao, Wei Bao, Shuang Yang, Haidan Shi, Dongfang Hao, Xiujuan Zhao and Yonghui Wu, (2013) The plasma metabolic profiling of chronic acephate exposure in rat via ultra-performance liquid chromatography -mass spectrometry based metabonomic method: Molecular BioSystem 1-35.

24. Wook-Joon Y., I.C. Lee, J. Lee, S. M. Lee, S.H. Kim, H. SeonBaek, C. Moon, Y.H. Chung, and J.C. Kim, (2013) Biochemical studies in rats following oral administration of 1,4-dichlorbutane. Lab Anim Res. 29(1): 48-54

\section{How to cite this article:}

Londhe, S. A., G. R. Gangane and Moregaonkar, S. D. 2020. Subacute Toxicity Assessment of Acephate and it's Amelioration by Picrorhiza kurroa in Female Wistar Rats. Int.J.Curr.Microbiol.App.Sci. 9(12): 3242-3250. doi: https://doi.org/10.20546/ijcmas.2020.912.386 